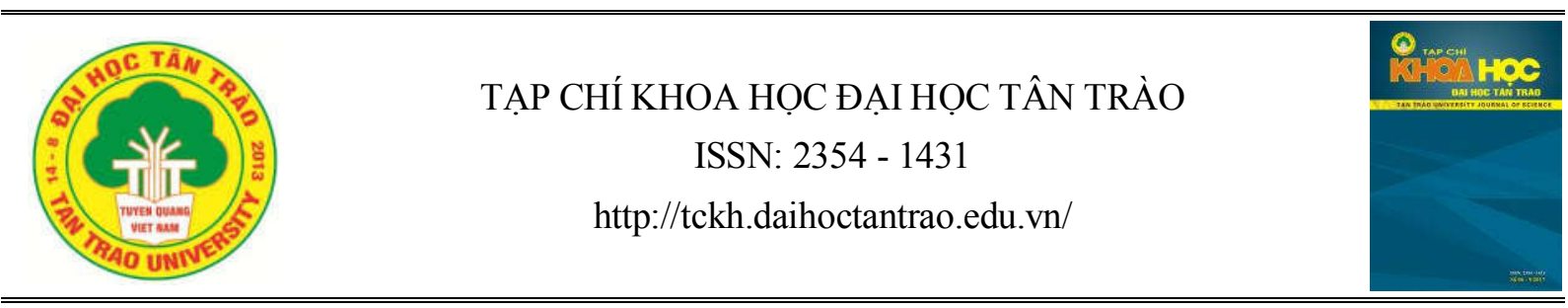

\title{
Biện pháp nâng cao chất lượng dạy học tích hợp kỹ năng sống cho học sinh tiểu học
}

Chu Thị Mỹ Nga $a^{a^{*}}$

a Truò̀ng Đại học Tân Trào

*Email: chumynga82@gmail.com

\section{Thông tin bài viết}

Ngày nhận bài:

21/5/2019

Ngày duyệt đăng:

$10 / 6 / 2019$

Tù khóa:

Kỹ năng sống; day học tích hơp; học sinh tiểu học; các biện pháp

\section{Tóm tắt}

Trong thời đại cách mạng công nghệ 4.0 hiện nay, học sinh tiểu học được tiếp xúc với xã hội rất sớm, cho nên giáo dục kỹ năng sống cho trẻ thực sự rất cần thiết. Việc dạy học tích hợp kỹ năng sống cơ bản cho học sinh tiểu học trên lớp và sinh hoạt, trải nghiệm ngoại khóa không chỉ mang lại lợi ích về mặt sức khoẻ mà còn giúp các em sớm có ý thức để làm chủ bản thân, sống tích cực và hướng đến những điều lành mạnh cho chính mình cũng như xã hội. Để làm tốt những yêu cầu này cần có các biện pháp nâng cao chất lượng dạy học tích hợp kỹ năng sống cho học sinh tiểu học. Nhà trường, giáo viên và các lực lượng giáo dục khác cần có những phối hợp đồng bộ để tạo điều kiện cho học sinh tiểu học trải nghiệm thực tế nhằm tạo nên vốn sống, nảy nở các phẩm chất, kỹ năng sống làm nền tảng cho sự phát triển nhân cách.

\section{1. Đặt vấn đề}

Dạy kỹ năng sống cho học sinh trong giai đoạn hiện nay là một yêu cầu cấp thiết ở các trường phổ thông nói chung, bậc tiểu học nói riêng. Trong khi nội dung về rèn luyện kỹ năng sống chưa được đưa vào thành một chương trình riêng mà chủ yếu được giáo viên lồng ghép trong từng bộ môn như giáo dục Đạo đức, Tiếng Việt... hay trong các tiết chào cờ đầu tuần, các buổi ngoại khóa. Với thời lượng quy định của một tiết học hiện nay, khi giáo viên lên lớp, sẽ không đủ thời gian để trang bị cho học sinh các kỹ năng sống đã gây ra những hạn chế cho quá trình dạy học tích hợp kỹ năng sống cho học sinh tiểu học.

Để đáp ứng được yêu cầu của quá trình dạy học tích hợp kỹ năng sống cho học sinh tiểu học, người giáo viên cần phải có các biện pháp nâng cao chất lượng dạy học tích hợp mới phát huy được hiệu quả ngay trong khuôn khổ những tiết dạy chính khóa. Do vậy, tất cả các giáo viên, người làm công tác quản lý giáo dục đều phải nắm vững được các biện pháp mang tính cốt lõi để triển khai dạy học tích hợp giúp cho học sinh tiểu học rèn luyện được kỹ năng sống.
2. Biện pháp nâng cao chất lượng dạy học tích hợp kỹ năng sống cho học sinh tiểu học.

\subsection{Các khái niệm công cụ}

Trong một vài năm trở lại đây, chúng ta thường xuyên được nghe đến cụm từ quen thuộc như giáo dục kỹ năng sống, dạy học tích hợp trong giáo dục. Đó là những phương thức hoạt động dạy tích hợp trong môn học và tích hợp liên môn, dạy học tích hợp kỹ năng sống. Chúng ta có thể hiểu một cách khái quát các khái niệm như sau:

- Kỹ năng sống: Có nhiều quan niệm khác nhau về kỹ năng sống:

Theo Tổ chức Y tế thế giới (WHO), Kỹ năng sống là khả năng để có hành vi thích ứng (adaptive) và tích cực (positive), giúp các cá nhân có thể ứng xử hiệu quả trước các nhu cầu và thách thức của cuộc sống hàng ngày.[6]

Theo Quỹ nhi đồng Liên hợp quốc (UNICEF), kỹ năng sống là cách tiếp cận giúp thay đổi hoặc hình thành hành vi mới. Cách tiếp cận này lưu ý đến sự cân bằng về tiếp thu kiến thức, hình thành thái độ và kỹ 
năng. Từ những khái niệm trên đây có thể thấy, kỹ năng sống bao gồm một loạt các kỹ năng cụ thể, cần thiết cho cuộc sống hàng ngày của con người. Bản chất của kỹ năng sống là kỹ năng tự quản lí bản thân và kĩ năng xã hội cần thiết để cá nhân tự lực trong cuộc sống, học tập và làm việc hiệu quả.

- Giáo dục kỹ năng sống: là một quá trình tác động sư phạm có mục đích, có kế hoạch nhằm hình thành năng lực hành động tích cực, có liên quan tới kiến thức và thái độ, giúp cá nhân có ý thức về bản thân, giao tiếp, quan hệ xã hội, thực hiện công việc, ứng phó hiệu quả với các yêu cầu thách thức của cuộc sống hàng ngày... Giáo dục kỹ năng sống là hoạt động giáo dục giúp cho người học hình thành và phát triển những thói quen, hành vi, thái độ tích cực, lành mạnh trong việc ứng xử các tình huống của cuộc sống cá nhân và tham gia đời sống xã hội, qua đó hoàn thiện nhân cách và định hướng phát triển bản thân tốt hơn dựa trên nền tảng các giá trị sống[7].

Giáo dục kỹ năng sống là rất quan trọng và cần thiết cho trẻ nhỏ. Giáo dục kỹ năng sống giúp cho học sinh tiểu học phát triển nhân cách, thể chất, tình cảm, giao tiếp, ngôn ngữ, tư duy một cách toàn diện, là nền tảng để trẻ tự tin tham gia vào các hoạt động sống và học tập.

- Day học tích hơp: Theo từ điển Giáo dục học: Tích hợp là hành động liên kết các đối tượng nghiên cứu, giảng dạy, học tập của cùng một lĩnh vực hoặc vài lĩnh vực khác nhau trong cùng một kế hoạch dạy học. [8] Dạy học tích hợp là một quan điểm lý luận dạy học, hành động liên kết các đối tượng nghiên cứu, giảng dạy, học tập của cùng một lĩnh vực hoặc vài lĩnh vực khác nhau trong cùng một kế hoạch dạy học. Như vậy, dạy học tích hợp là nói đến việc sử dụng các phương pháp và mục tiêu của hoạt động dạy học của giáo viên tích hợp nội dung dạy học với việc hình thành các kỹ năng cho học sinh tiểu học. Giáo viên có thể tích hợp các nội dung ở các môn học khác nhau, hoặc các kiến thức khác liên quan đến bài giảng để chuyển tải đến học sinh những chủ đề giáo dục lồng ghép thông qua các hình thức truyền đạt bằng trình chiếu, giảng dạy, thảo luận, dạy học theo dự án.... Dạy học tích hợp là một xu hướng của lí luận dạy học và được nhiều nước trên thế giới thực hiện.

- Dạy học tích hơp kỹ năng sống ở tiểu họ: Dạy học tích hợp kỹ năng sống cho học sinh tiểu học là cách thức dạy lồng ghép những nội dung giáo dục có liên quan đến quá trình dạy học của một môn học như: Giáo dục đạo đức, lối sống; giáo dục môi trường; tiết kiệm và sử dụng năng lượng ... nhằm giúp học sinh hình thành các kỹ năng sống thông qua việc xử lí các nội dung kiến thức trong mối liên quan với nhau, đảm bảo học sinh tiểu học vận dụng được tổng hợp các kiến thức đó một cách hợp lí để giải quyết các vấn đề trong học tập, cuộc sống.[1]

\subsection{Các kỹ năng sống cốt lôi cần giáo dục cho học sinh tiểu học}

Việc rèn luyện kỹ năng sống cho học sinh ở bậc Tiểu học không chỉ giúp trẻ hình thành nên những hành vi tích cực và khả năng thích nghi với mọi hoàn cảnh sống, tạo nên bản lĩnh tự tin hơn để khám phá và tận hưởng cuộc sống một cách trọn vẹn. Xuất phát từ mục đích dạy học tích hợp kỹ năng sống cho học sinh Tiểu học, nhà trường cũng như giáo viên cần tạo ra một môi trường trải nghiệm giúp trẻ hoàn thiện khả năng tự chủ của bản thân, phát triển nhân cách và thích nghi với một cuộc sống luôn thay đổi.

Có thể nhận diện các kỹ năng sống cơ bản, cốt lõi cần giáo dục cho học sinh tiểu học qua các kỹ năng dưới đây:

Kỹ năng ứng xử nơi học đường; Kỹ năng giao tiếp tạo dựng các mối quan hệ; Kỹ năng trình tự nhận thức; Kỹ năng thuyết trình; Kỹ năng phòng chống xâm hại; Kỹ năng học trên lớp và tự học ở nhà; Kỹ năng xây dựng sự tự tin và coi trọng giá trị bản thân; Kỹ năng thích ứng với mọi môi trường, điều kiện sống khác nhau; Kỹ năng đặt mục tiêu trong công việc, học tập; Kỹ năng giải quyết vấn đề; Kỹ năng làm việc nhóm; Kỹ năng lãnh đạo và hành vi tích cực; Tinh thần trách nhiệm và kỹ năng tổ chức công việc hiệu quả; Nhận thức giới tính và nhận thức cảm xúc học đường; Kỹ năng tự chăm sóc bản thân; Kỹ năng cứu thương: Sơ cấp cứu, xử lý tình huống, cấp cứu đuối nước, băng bó vết thương, cách xử lý khị bị điện giật- cháy bỏng; Kỹ năng sinh hoạt tập thể...

Ở mỗi cách tiếp cận khác nhau đều có thể giáo dục kỹ năng sống phù hợp với môi trường học tập và sinh sống của học sinh. Về cơ bản, khi dạy học tích hợp, nhà trường và giáo viên cần xây dựng chương trình giáo dục các kỹ năng sống cần thiết, cốt lõi nhằm tăng cường năng lực và khả năng thích ứng cho học sinh tiểu học.

Từ chương trình giáo dục phổ thông mới, từ các đặc điểm môn học, cần tổ chức các phương pháp, biện pháp dạy nhằm nâng cao hiệu quả giáo dục tích hợp kỹ năng sống cho học sinh tiểu học và thể hiện được sự phân hóa trong quá trình dạy học. Về phương pháp và hình 
thức tổ chức dạy học, đối với một chủ đề, người giáo viên luôn phải chú trọng việc ứng dụng kiến thức của chủ đề vào thực tiễn cũng như ứng dụng kết hợp với các môn học khác nhằm tăng cường kỹ năng sống cho học sinh tiểu học.

\subsection{Nhũng yêu cầu của chuơng trình dạ học tích} hợp đối với việc rèn luyện kỹ năng sống cho học sinh tiểu học

Bộ GD\&ĐT đã công bố nội dung chương trình các môn học và lộ trình thực hiện triển khai chương trình mới. Trong đó, hoạt động trải nghiệm cũng là một nội dung quen thuộc vì được xây dựng trên cơ sở các hoạt động giáo dục tập thể như chào cờ, sinh hoạt lớp, sinh hoạt Sao Nhi đồng, Đội TNTP Hồ Chí Minh và các hoạt động tham quan, lao động, thiện nguyện, phục vụ cộng đồng,... trong chương trình hiện hành. Ở cấp tiểu học, nội dung các môn học bao giờ cũng gắn tích hợp kỹ năng sống và hoạt động trải nghiệm cho học sinh.

Những yêu cầu dạy học tích hợp phải đáp ứng được yêu cầu rèn kỹ năng sống cho học sinh tiểu học mà kết quả của hoạt động dạy học đó cần thể hiện được kết qua khi học sinh tham gia vào các hoạt động trải nghiệm nhằm tăng cướng năng lực thích ứng với cuộc sống như: Hiểu biết về bản thân và môi trường sống; Nhận biết được sự thay đổi của cơ thể, cảm xúc, suy nghĩ của bản thân; Hình thành được một số thói quen, nếp sống sinh hoạt và kĩ năng tự phục vụ; Nhận ra được nhu cầu phù hợp và nhu cầu không phù hợp; Phát hiện được vấn đề và tự tin trao đổi những suy nghĩ của mình; Chỉ ra được sự khác biệt giữa các cá nhân về thái độ, năng lực, sở thích và hành động; Nhận diện được một số nguy hiểm từ môi trường sống đối với bản thân; Kĩ năng điều chỉnh bản thân và đáp ứng với sự thay đổi; Đề xuất được những cách giải quyết khác nhau cho cùng một vấn đề; Làm chủ được cảm xúc, thái độ và hành vi của mình và thể hiện sự tự tin trước đông người; Tự lực trong việc thực hiện một số việc phù hợp với lứa tuổi; Biết cách thoả mãn nhu cầu phù hợp và kiềm chế nhu cầu không phù hợp; Thực hiện được các nhiệm vụ với những yêu cầu khác nhau; Biết cách xử lí trong một số tình huống nguy hiểm.

Theo chương trình giáo dục phổ thông mới, hoạt động dạy học tích hợp ở tiểu học, cần tăng cường tích hợp trong nội bộ môn học Toán, Tiếng Việt, Đạo đức, Tự nhiên và Xã hội (các lớp $1,2,3$ ) và lồng ghép các vấn đề như môi trường, biến đổi khí hậu, kĩ năng sống, dân số, sức khỏe sinh sản... vào các môn học và hoạt động giáo dục.
Lớp 4 và lớp 5 , thực hiện điều chỉnh và hình thành hai môn: Khoa học và Công nghệ (chủ yếu dựa trên cơ sở môn học này ở các lớp 4,5 của chương trình hiện hành); Tìm hiểu xã hội (chủ yếu dựa trên cơ sở môn Lịch sử và Địa lý các lớp 4,5 của chương trình hiện hành và thêm một số vấn đề xã hội).[1]

Để đáp ứng được các yêu cầu trên, người giáo viên tiểu học cần tập trung xây dựng các chủ đề dạy học trong mỗi môn học và chủ đề kỹ năng sống để dạy tích hợp cho phù hợp với điều kiện, hoàn cảnh của địa phương, nhà trường. Người giáo viên cần chuẩn bị tâm thế vui vẻ trong tổ chức dạy tích hợp vì sẽ mất nhiều thời gian chuẩn bị. Cách thức dạy tích hợp phải duy trì sự ổn định cho lớp học luôn sôi động, các em học sinh hào hứng học tập. Như vậy, vai trò của các biện pháp dạy học tích hợp kỹ năng sống cho học sinh tiểu học có ý nghĩa vô cùng quan trọng.

\subsection{Biện pháp giúp giáo viên dạy học tích hợp rèn} luỵ̣̂n kỹ năng sống cho học sinh tiểu học

Thực tế các kỹ năng sống đã được đưa vào mục tiêu cụ thể ở từng môn học, bài học nhưng thực tế, vẫn có hiện tượng giáo viên khi dạy tích hợp đã không có sự cân nhắc, lựa chọn trong một bài dạy nên dạy không đủ giờ, cái chính chưa nói được bao nhiêu mà phần tích hợp đã làm biến dạng tiết học, không đạt được hiệu quả rèn kỹ năng sống cho học sinh. Vì vậy, để có hiệu quả cao, người giáo viên cần nắm vững các biện pháp sau:

\subsubsection{Tăng cuò̀ng nâng cao nghiệp vu và tâm lý học} su pham

Để truyền đạt được kiến thức và giúp học sinh tiểu học đam mê học tập, người giáo viên phải có nghiệp vụ sư phạm vững vàng, phải tự bồi dưỡng và trang bị cho mình phương pháp dạy học sinh động, có cách giảng bài một cách ngắn gọn, xúc tích để bài học dễ đi sâu vào trí nhớ.

Ngoài năng khiếu, có thể nói tính cách của thầy cô tựa như nguồn cảm hứng, tác động lớn nhất đến việc học của trẻ. Sự vui vẻ, hài hước là liều thuốc tốt nhất cho giáo dục học sinh. Giáo viên phải là người am hiểu tâm sinh lý học sinh, đặc biệt phải thật tinh ý nắm được tâm tư của trẻ, chỉ bảo khéo léo, thu hút được các em tham gia vào từng nội dung của bài học. Giáo viên càng hài hước, dí dỏm học sinh càng thích học môn đó. Có thể áp dụng phương pháp "lớp học vui vẻ', "vừa học vừa chơi". Phương pháp này giúp trẻ dễ tiếp thu mà còn giúp trẻ chủ động, vận động não bộ nhiều hơn theo chiều hướng tích cực. 
2.4.2. Giáo viên cần đổi mới cách thức, hình thức triển khai nội dung bài giảng dạy tích hợ kỹ năng sống cho hoc sinh tiểu học.

- Thầy cô giáo là người mẹ hiền thứ hai của học sinh tiểu học, các em luôn luôn nghe lời dạy bảo và làm theo những gì thầy cô dạy. Do đó, thầy cô giáo phải là tấm gương sáng về đạo đức, nhất là tấm gương về các ứng xử văn hóa, chuẩn mực trong lời nói và việc làm. Giáo dục kỹ năng sống cho học sinh sẽ khó hơn khi chính thầy cô không phải là một tấm gương.

- Để tạo cho các em môi trường năng động cũng như tạo niềm vui, hứng thú trong học tập, mỗi người giáo viên cần không ngừng đổi mới phương pháp dạy học theo hướng phát huy tính độc lập, sáng tạo của học sinh gắn với thực tiễn, có tài liệu bổ trợ phong phú, sử dụng thiết bị dạy học và ứng dụng CNTT trong dạy học.

- Trong công tác chuẩn bị bài lên lớp, giáo viên cần thiết kế tiến trình dạy học thành các hoạt động học của học sinh, xây dựng các nội dung chính để giảng dạy; xác định những năng lực có thể nâng cao cho học sinh trong từng nội dung. Biên soạn các câu hỏi, bài tập để đánh giá trình độ của học sinh; tổ chức dạy học để dự giờ, phân tích, rút kinh nghiệm.

- Mỗi bài dạy, giáo viên luôn chú trọng tạo cho các em tính chủ động, tích cực, hứng thú trong học tập; phát huy tính sáng tạo. Trong giờ học, giáo viên cần tạo cơ hội cho các em được nói, được trình bày trước nhóm bạn, trước tập thể, nhất là các em còn hay rụt rè, khả năng giao tiếp kém qua đó góp phần tích lũy thêm kỹ năng sống.

- Giáo viên chủ nhiệm phải làm tốt công tác chủ nhiệm mà nhà trường phân công, thường xuyên thay đổi các hình thức sinh hoạt lớp để các em được thay mặt lớp trực đánh giá, nhận xét thêm phần giao lưu với toàn trường qua các tiết mục văn nghệ, kể chuyện, câu đố, trò chơi... do chính các em đứng ra tổ chức dưới sự giúp đỡ và hướng dẫn của giáo viên.

- Quán triệt mục tiêu giảng dạy môn Đạo đức, nhất là hình thành các hành vi đạo đức. Giáo viên làm tốt công tác kiểm tra đánh giá phân loại hạnh kiểm của học sinh, rèn cho các em khả năng tự học, tự chăm sóc bản thân, biết lễ phép, hiếu thảo, tự phục vụ bữa ăn và vệ sinh cá nhân. Thay đổi luân phiên nhau cho học sinh có cơ hội thử thách làm lớp trưởng, tổ trưởng, để các em rèn luyện tác phong của người biết tích cực chủ động, sáng tạo trong cách điều hành nhóm và tập thể lớp.
2.4.3. Nhà trưòng tăng cưòng tổ chức các hoạt động trải nghiệm, đa dạng hóa các hoạt động tập thể trong và ngoài nhà trừ̀ng

- Nhà trường cần tổ chức tốt các buổi chào cờ đầu tuần. Theo đó mục tiêu buổi chào cờ không chỉ là đánh giá xếp loại nền nếp, học tập, các hoạt động giáo dục trong tuần qua, triển khai kế hoạch tuần tới của $\mathrm{BGH}$ nhà trường mà cần thay đổi hình thức buổi lễ chào cờ một cách sáng tạo, rèn luyện các kỹ năng cho học sinh.

- Tổ chức tốt hoạt động ngoại khóa, “diễn đàn” ở phạm vi lớp khối của mình. Mỗi năm học sẽ có một số chủ đề rèn luyện kỹ năng sống được triển khai. Trong đó nhà trường cần phát huy vai trò của tổ chức Đội TNTP Hồ Chí Minh và Sao nhi đồng theo các chủ điểm hàng tháng.

+ Xây dựng trường, lớp xanh-sạch-đẹp-an toàn. Trong đó cần chú trọng tạo môi trường tự nhiên gần gũi với cuộc sống như trồng vườn cây thuốc nam, các câu khẩu hiệu ở các cây xanh, bồn hoa để thông qua đó mà giáo dục ý thức BVMT ở các em.

\subsubsection{Thành lạp các loại hình câu lạc bộ, nhóm} sinh hoạt tập thể

Nhà trường nên thành lập các câu lạc bộ cho học sinh tiểu học như khiêu vũ thể thao, tiếng Anh, âm nhạc, hội họa, kỹ năng sống, trò chơi dân gian, hát dân ca và các loại hình sinh hoạt văn hóa dân gian vào trường học...giúp học sinh có cơ hội thể hiện đam mê của mình. Nhà trường cần thường xuyên tổ chức các hoạt động cho các câu lạc bộ và nhóm học sinh được tham gia vào các phong trào nâng cao thể chất, các buổi tham quan dã ngoại. Tổ chức sinh hoạt chuyên đề với các trường học khác để câu lạc bộ của học sinh tiểu học được học hỏi lẫn nhau qua các hoạt động giao lưu, qua đó rèn luyện kỹ năng sống cho các em. Những hoạt động của câu lạc bộ, nhóm sinh hoạt thực tế sẽ giúp học sinh tiểu học được hòa mình vào không khí tập thể, trải nghiệm trong từng cảm xúc và thể hiện kỹ năng sống, từ đó các em sẽ tích lũy vốn sống, tạo nền tảng cho sự phát triển nhân cách.

Ngoài ra, nhà trường cần phối hợp với gia đình, các tổ chức xã hội trong và ngoài nhà trường để cùng góp phần giáo dục kỹ năng sống cho các em. Hàng năm các nhà trường tổ chức cho các em đi du lịch trải nghiệm để các em có những cảm nhận tốt đẹp về quê hương đất nước, thêm lòng thương yêu và tự hào về tổ quốc.

\section{Kết luận}

Dạy học tích hợp cần phải được tiến hành rất kỹ lưỡng dựa trên cơ sở kiến thức khoa học cơ bản kết hợp với rèn kỹ năng sống cho học sinh tiểu học. Các biện 
pháp nâng cao chất lượng dạy học tích hợp kỹ năng sống cho học sinh tiểu học giúp giáo viên biết xây dựng biện pháp, cách thức dạy tích hợp kỹ năng sống khác nhau đạt được mục đích giáo dục.

Sau khi nắm vững các biện pháp dạy học tích hợp kỹ năng sống, người giáo viên cần phát huy tốt vai trò người tổ chức rèn luyện kỹ năng sống cho học sinh tiểu học, đặc biệt quan tâm đến hoạt động thực hành và ứng dụng kiến thức vào giải quyết những vấn đề thực tiễn. Nhà trường cần tổ chức những hoạt động trải nghiệm đa dạng về hình thức, phong phú về nội dung, tạo được các động lực, các điều kiện giúp giáo viên dạy học tích hợp kỹ năng sống cho học sinh đạt được hiệu quả cao hơn.

\section{TÀI LIỆU THAM KHẢO}

1. Bộ Giáo dục và Đào tạo, Chưong trình giáo dục phổ thông - Chương trình tổng thể, 2017.

2. Nguyễn Văn Cường - Bernd Meier, Lý luận dạy học hiện đại-cơ sở đổi mói mục tiêu, nội dung và phưong pháp dạy học, Nxb Đại học Sư phạm, Hà Nội, 2014.
3. Nguyễn Anh Dũng (chủ nhiệm), Phuoong án thưc hiện quan điểm tích hợp trong phát triển chuoong trình giáo dục phổ thông Việt Nam giai đoạn sau năm 2015, Đề tài NCKH cấp Bộ, mã số: B2011-07NV, Viện Khoa học Giáo dục Việt Nam, 2013.

4. Nguyễn Văn Đản, Tổ chức hoạt động học, Nxb Giáo dục Việt Nam, Hà Nội, 2012.

5. Nguyễn Đức Minh (chủ biên), Dương Văn Hưng, Trần Hải Toàn, Đổi mới đánh giá kết quả giáo dục học sinh tiểu học, Nxb Giáo dục Việt Nam, Hà Nội, 2015.

6. Life Skills Education for Children and Adolescents in Schools, World Health Organization, 1997.

7. Thông tư số 04/2014/TT-BGDĐT do Bộ Giáo dục và Đào tạo ban hành ngày $28 / 2 / 2014$ về việc ban hành quy định quản lý hoạt động giáo dục kỹ năng sống và hoạt động giáo dục ngoài giờ chính khóa.

8. Bùi Hiển (2013), Từ điển Giáo dục học, Nhà xuất bản Từ điển Bách Khoa.

\section{Methods to improve the quality of teaching life skills integration for elementary students}

Chu Thi My Nga

\section{Article info}

Recieved:

21/5/2019

Accepted:

$10 / 6 / 2019$

Keywords:

Life skills;

integrated teaching;

primary student;

methods

\begin{abstract}
In the era of technology revolution 4.0, primary students are exposed to society very soon, so educating life skills for children is really necessary. Teaching integrates basic life skills for elementary school students in class and activities, extracurricular experiences not only bring health benefits but also help children to consciously master themselves, living positively and towards healthy things for yourself and society. In order to well fulfill these requirements, it is necessary to take measures to improve the quality of life skills integration teaching for elementary students. Schools, teachers and other educational forces need to have coordinate coordination to facilitate primary school students to experience real life in order to create a living, developing qualities and life skills as a foundation for personality development.
\end{abstract}

